\title{
Add-on histamine receptor-3 antagonist for allergic rhinitis: a double blind randomized crossover trial using the environmental exposure unit
}

Michelle L North ${ }^{1,2}$, Terry J Walker², Lisa M Steacy², Barnaby G Hobsbawn², Richard J Allan ${ }^{3}$, Frances Hackman ${ }^{3}$, Xiaoqun Sun ${ }^{4}$, Andrew G Day ${ }^{4}$ and Anne K Ellis ${ }^{1,2,5^{*}}$

\begin{abstract}
Background: Oral antihistamines that target the histamine receptor-1, such as fexofenadine, offer suboptimal relief of allergic rhinitis-associated nasal congestion. Combinations with oral sympathomimetics, such as pseudoephedrine, relieve congestion but produce side effects. Previous animal and human studies with histamine receptor-3 antagonists, such as PF-03654764, demonstrate promise.

Methods: Herein we employ the Environmental Exposure Unit (EEU) to conduct the first randomized controlled trial of PF-03654764 in allergic rhinitis. 64 participants were randomized in a double-blind, placebo-controlled 4-period crossover study. Participants were exposed to ragweed pollen for 6 hours post-dose in the EEU. The primary objective was to compare the effect of PF-03654764 + fexofenadine to pseudoephedrine + fexofenadine on the subjective measures of congestion and Total Nasal Symptom Score (TNSS). The objectives of our post-hoc analyses were to compare all treatments to placebo and determine the onset of action (OA). This trial was registered at ClinicalTrials.gov (NCT01033396).

Results: PF-03654764 + fexofenadine was not superior to pseudoephedrine + fexofenadine. In post-hoc analyses, PF-03654764 + fexofenadine significantly reduced TNSS, relative to placebo, and OA was 60 minutes. Pseudoephedrine + fexofenadine significantly reduced congestion and TNSS, relative to placebo, with OA of 60 and 30 minutes, respectively. Although this study was not powered for a statistical analysis of safety, it was noted that all PF-03654764-treated groups experienced an elevated incidence of adverse events.

Conclusions: PF-03654764 + fexofenadine failed to provide superior relief of allergic rhinitis-associated nasal symptoms upon exposure to ragweed pollen compared to fexofenadine + pseudoephedrine. However, in post-hoc analyses, PF-03654764 + fexofenadine improved TNSS compared to placebo. Side effects in the PF-03654764-treated groups were clinically significant compared to the controls.
\end{abstract}

Keywords: Allergic rhinitis, Environmental exposure unit, Fexofenadine, PF-03654764, pseudoephedrine, $\mathrm{H}_{3}$ receptor, $\mathrm{H}_{1}$ receptor, Ragweed, Nasal congestion, Decongestant

\footnotetext{
* Correspondence: ellisa@queensu.ca

'Department of Biomedical and Molecular Sciences, Queen's University, Kingston, Ontario, Canada

${ }^{2}$ Allergy Research Unit, Kingston General Hospital, Kingston, Ontario, Canada

Full list of author information is available at the end of the article
} 


\section{Introduction}

Allergic rhinitis is characterized by IgE and histaminemediated symptoms such as rhinorrhea, sneezing, nasal pruritus, congestion, and aggravation of comorbid asthma [1]. Histamine interacts with 4 receptor subtypes, designated, $\mathrm{H}_{1}, \mathrm{H}_{2}, \mathrm{H}_{3}$ and $\mathrm{H}_{4}$. Antihistamines affecting the $\mathrm{H}_{1}$ receptor are widely used for acute relief of allergic rhinitis [2]. These agents, including fexofenadine, effectively reduce sneezing and rhinorrhea, but have limited effectiveness against congestion [3-6]. Congestion may be mediated by dilatation of venous capacitance vessels and extravascular plasma leak [7]. As vascular tone is under sympathetic neural control, traditional antihistamines have been combined with sympathomimetic decongestants such as pseudoephedrine $[8,9]$. However, due to side effects such as insomnia and hypertension, these agents are contraindicated in those with cardiovascular problems [8-11]. The development of $\mathrm{H}_{3}$ receptor antagonists as decongestants may represent a significant advance in available treatments.

Animal models demonstrated that $\mathrm{H}_{3}$ receptor antagonists inhibit nasal congestion in combination with antihistamines that target the $\mathrm{H}_{1}$ receptor [12-15]. Activation of the prejunctional histamine $\mathrm{H}_{3}$ receptors modulates sympathetic control of nasal vascular tone and resistance [15]. Oral administration of molecules that interfere with both the $\mathrm{H}_{1}$ and $\mathrm{H}_{3}$ receptors significantly attenuated total nasal symptoms, and nasal blockage, relative to placebo, but did not provide greater relief than cetirizine [16]. Thus, the present study was targeted towards examining a specific $\mathrm{H}_{3}$ receptor antagonist using an alternate active control, pseudoephedrine + fexofenadine, which is known to relieve congestion.

PF-03654764 is a potent and specific $\mathrm{H}_{3}$ receptor antagonist, with $>1000$-fold selectivity for the $\mathrm{H}_{3}$ receptor over the other histamine receptor subtypes [17]. A previous clinical trial employing a nasal ragweed bolus after administration of PF-03654746 (an $\mathrm{H}_{3}$ receptor antagonist with similar structure to PF-03654764) + fexofenadine demonstrated significantly reduced congestion, compared to placebo [11]. However, PF-03654764 has never been tested in a randomized controlled trial of allergic rhinitis, or in the Environmental Exposure Unit (EEU), which better approximates real life by delivering the allergen in the ambient air $[18,19]$. Therefore, our primary objective was to compare the effect of PF03654764 + fexofenadine to pseudoephedrine + fexofenadine, on subjective measures of allergen-induced congestion and Total Nasal Symptom Score (TNSS) in the EEU, a sensitive, specific and reproducible methodology for allergen challenge. An exposure period of 6 hours post administration of study medication also enabled us to assess the onset of action.

\section{Methods \\ Additional experimental details are available in an online data supplement}

All study procedures were approved by the Queen's University Health Sciences and Affiliated Teaching Hospitals Human Research Ethics Board and all participants provided written informed consent before undergoing any study-specific procedures. This trial was registered at ClinicalTrials.gov (NCT01033396).

\section{Participant selection and enrollment}

Exposure to ragweed pollen in the EEU is a well-tolerated, well-validated and reproducible method to elicit symptoms in a cohort of individuals with ragweed-induced allergic rhinitis [18]. Study participants were recruited from an existing database of potential research participants in the Allergy Research Unit, Kingston General Hospital, through posters placed throughout Kingston, Ontario, and the Queen's University campus, as well as through local radio, and newspaper advertisements. The study was conducted out of ragweed season. Briefly, exclusion criteria included asthma requiring more than 3 uses per week of short acting inhaled $\beta$-agonists and severe hypertension. Blood pressure (BP) was measured at screening, pre and post-study period (pollen exposures), and follow-up.

\section{Dose selection}

Doses of fexofenadine $(60 \mathrm{mg})$ and pseudoephedrine $(120 \mathrm{mg})$ were based on commercially available preparations. Previous drug-drug interaction (DDI) studies were not performed with PF-03654764. However, the similar $\mathrm{H}_{3}$ receptor antagonist, PF-03654746 was administered in combination with fexofenadine by Stokes et al. [11]. Pharmacokinetic drug interaction studies demonstrated low potential of PF-03654764 to inhibit activities of CYP 1A2, 2B6, 2C8, 2C9, 2C19, 2D6, and 3A4 based on IC50 values $>30 \mu \mathrm{M}$ versus the projected clinically efficacious concentration of $2.3 \mathrm{nM}$ [20]. Nevertheless, participants were asked to abstain from grapefruit-related citrus fruits from 7 days prior to the first dose until collection of the final pharmacokinetic blood sample. The oral dose of $5 \mathrm{mg}$ PF-03654764 was chosen to yield a mean maximum plasma concentration of $14 \mathrm{ng} / \mathrm{mL}$, approximately $10 \times \mathrm{Ki}$ (10 times the binding affinity of PF-03654764 for the $\mathrm{H}_{3}$ receptor). This dose had previously been tested upon single and repeat dosing in healthy volunteers and had been generally safe and well tolerated [20]. Participants were instructed to abstain from all food and drink (except water) for 2 hours prior to dosing. Plasma clearance and half-life for PF-03654764 in humans were projected to be $3 \mathrm{~mL} / \mathrm{min} / \mathrm{kg}$, and 16 hours, respectively [20]. 


\section{Priming visits}

During a maximum of five priming visits, study participants were exposed to a target concentration of $3500 \pm$ 500 grains $/ \mathrm{m}^{3}$ of ragweed pollen (Ambrosia artemisiifolia, Greer Laboratories, Lenoir, North Carolina) for up to 3 hours, while recording their symptoms at baseline and every 30 minutes thereafter. Symptom score endpoints consisted of a four point $(0-3)$ self-reported scale (definitions provided in Additional file 1: Table S4), for each of the following symptoms: congestion, sneezing, nasal itch, rhinorrhea. Total nasal symptom score (TNSS) was the sum of the scores for sneezing, nasal itch and rhinorrhea (maximum score of 9). Participants who did not achieve a TNSS equal to or greater than 4 and a congestion score equal to or greater than 2 at the 90-minute time point during at least one priming visit were excluded from the study to ensure medication effects would be discernible.

\section{Study periods}

The first study period took place within 12 days of priming and periods were separated by 2 -weeks. Participants were exposed to a target concentration of $3500 \pm 500$ grains $/ \mathrm{m}^{3}$ of ragweed pollen for eight hours $(-2 \mathrm{H}$ to $6 \mathrm{H}$, with administration of medication at $0 \mathrm{H}$ ). Participants were not randomized until rhinitis symptoms were verified just prior to dosing (TNSS $\geq 4$ and a congestion score $\geq 2$ at the 90-minute time point). To maintain participant and investigator blinding, three pills, identical in appearance, were dispensed from three pairs of bottles (active vs placebo for each of three active treatments). Participants were allocated to a treatment sequence using a computer-generated randomization schedule (Table 1). The allotment of participants to different treatment sequences was not equal in order to give more power to the primary comparison (fexofenadine + pseudoephedrine $v s$. fexofenadine + PF-03654764).

\section{Table 1 Sequences of study treatment administrations}

\begin{tabular}{llllll}
\hline Sequence & $\begin{array}{l}\text { Number of } \\
\text { participants }\end{array}$ & \multicolumn{4}{l}{ Study period } \\
\cline { 3 - 6 } & 4 & B & $\mathbf{2}$ & $\mathbf{3}$ & $\mathbf{4}$ \\
\hline $\mathbf{1}$ & 4 & B & B & C & D \\
$\mathbf{2}$ & 4 & C & B & D & B \\
$\mathbf{3}$ & 4 & D & C & B & B \\
$\mathbf{4}$ & 12 & A & C & A & C \\
$\mathbf{5}$ & 12 & C & A & C & A \\
$\mathbf{6}$ & 12 & A & C & C & A \\
$\mathbf{7}$ & 12 & C & A & A & C \\
$\mathbf{8}$ & 4 & &
\end{tabular}

A: PF-03654764 capsule $(5 \mathrm{mg})+$ fexofenadine capsule $(60 \mathrm{mg})+$ placebo capsule. B: PF-03654764 capsule (5 mg) + placebo capsule + placebo capsule.

C: placebo capsule + placebo capsule + fexofenadine $(60 \mathrm{mg}) /$ pseudoephedrine (120 mg) capsule.

D: placebo capsule + placebo capsule + placebo capsule.

\section{Statistics}

The sample size was calculated based on mean score from hour 2 to hour 6 for congestion and TNSS, and a Bayesian interpretation of the results, assuming a noninformative prior and a within-subject standard deviation of 0.7 . The primary efficacy analyses used sequences 5-8 and included all participants randomized who received at least one dose and who had at least one post-dose measurement. A mixed effect model was used, with participant as a random effect, period/treatment as fixed effects and baseline covariates. Baseline was calculated as the mean of the last two pre-treatment symptom scores $(-0.5 \mathrm{H}$ and $\mathrm{OH})$. The baseline covariates were:

Baseline mean = mean pre-dose value for each participant across the four periods

Baseline difference $=$ the difference between the pre-dose value at a given period and the participant's baseline mean

Differences between treatment means, standard errors (SE), and two-sided 90\% confidence intervals (CI) are presented.

In general, Studentized residuals are preferable to standardized residuals for purposes of outlier identification, and values of 3 or greater (or -3 or less) may be considered outliers [21]. Therefore, to avoid the situation where an extreme data point can be highly influential in the analysis, data points that met these criteria were excluded, and when this occurred, all data from the participant was removed. These exclusion criteria were decided upon $a$ priori in advance of study commencement.

The criteria used for evaluation of the efficacy and noninferiority of PF-03654764 + fexofenadine against congestion compared to existing treatment were:

Criteria 1: At least $80 \%$ sure that PF-03654764+ fexofenadine has a greater than 0.15 point reduction in congestion compared to pseudoephedrine + fexofenadine (for efficacy).

Criteria 2: At least $80 \%$ sure that PF-03654764+ fexofenadine was non-inferior to pseudoephedrine + fexofenadine, using a non-inferiority margin of -1 .

\section{Post-Hoc analyses}

The investigator's site undertook post-hoc analyses to compare all groups to placebo. Mean symptom scores were calculated by taking the least-squares mean between $2 \mathrm{H}$ and $6 \mathrm{H}$. Methods above were used for the post-hoc ANCOVA, except all groups were included to compare to placebo. Onset of action (OA) was calculated for treatments found to significantly relieve symptoms, defined as the median onset of a clinically important reduction (0.5 symptom score units from baseline for 
congestion; 1.0 for TNSS) across all participant study periods. All post-hoc analyses were conducted under the auspices of the investigator site. Graphing was performed using Prism Version 4.0c (GraphPad Inc., La Jolla, CA). All other statistical analyses were carried out using SAS Version 9.3 (SAS Institute Inc., Cary, NC).

\section{Results}

Demographic data on the participants in this study are presented in Table 2. All participants had a minimum 2 year history of allergic rhinitis to ragweed. The participants self-reported being diagnosed with allergic rhinitis by a physician between 6 and 56 years prior to enrolment in the study (mean duration 25.3 years). The average pollen concentrations determined via Rotorod $^{\circ}$ samplers in the EEU were $2913 \pm 216$ grains $/ \mathrm{m}^{3}$ for priming visits and $3348 \pm 103$ grains $/ \mathrm{m}^{3}$ for treatment visits.

\section{Symptom time-course}

During each study period, participants developed ragweedinduced symptoms of allergic rhinitis during the 2 hours prior to treatment $(-2 \mathrm{H}$ to $\mathrm{OH})$. The effectiveness of the different treatment arms against congestion and total nasal symptom scores (TNSS) over time can be visualized as the post-treatment change from baseline (Figure 1).

\section{Primary efficacy analysis}

The primary efficacy analysis employed treatment sequences 5-8 to compare PF-03654764 + fexofenadine to fexofenadine + pseudoephedrine. Six and nine participanttreatment periods were lost due to discontinuations, illnesses and contraindicated medication use in the PF-03654764 + fexofenadine and fexofenadine + pseudoephedrine groups, respectively. The exclusion of two outliers further reduced the PF-03654764 + fexofenadine group by four participant treatment periods. Thus, Table 3 presents the primary efficacy analyses derived from a total of 86 and 87 participant treatment periods, in the PF-03654764 + fexofenadine and fexofenadine + pseudoephedrine groups, respectively. PF-03654764 + fexofenadine was not effective in reducing nasal congestion compared to pseudoephedrine + fexofenadine (i.e., Criteria 1 was not met). However, PF-03654764 + fexofenadine

Table 2 Participant demographic data

\begin{tabular}{ll}
\hline Characteristic & Total $(\mathbf{n}=\mathbf{6 4})$ \\
\hline Age (years) & $39.7(19-59)$ \\
Female Sex (\%) & $51.6 \%$ \\
Caucasian (\%) & $90.6 \%$ \\
Body Mass Index $\left(\mathrm{kg} / \mathrm{m}^{2}\right)$ & $26.8(19.7-32.0)$ \\
\hline
\end{tabular}

Demographic data for participants in this study. Mean age in years (range). Body Mass Index in $\mathrm{kg} / \mathrm{m}^{2}$ (range). was shown to be non-inferior to pseudoephedrine + fexofenadine with respect to TNSS (i.e., Criteria 2 was met).

\section{Post-Hoc efficacy analysis}

The investigator's site undertook a post-hoc analysis, that was not part of the pre-specified statistical plan, to compare the treatments of interest to placebo. The sample size difference in the fexofenadine + pseudoephedrine group reflects the addition of participants from sequences $1-4$. In the placebo group 16 participants were assigned to treatment but one never received placebo, as they were assigned to sequence 2 and dropped out of the study after study period 2 . In the PF-03654764 group 16 participants were randomized but one discontinued during period 2 in sequence 4 and thus never received PF-03654764 during the following two periods (3 and 4). One participant in sequences 1-4 was excluded as an outlier according to the pre-specified exclusion criteria, reducing the sample sizes for placebo and PF-03654764 to 14 and 28, respectively. Pseudoephedrine + fexofenadine significantly reduced congestion and TNSS, compared to placebo (Table 4). PF-03654764 alone did not have a significant effect on symptoms. In the post hoc mixed model, the combination of PF-03654764 with fexofenadine significantly improved TNSS, but not congestion (Table 4).

\section{Onset of action}

The median onset of action for pseudoephedrine + fexofenadine regarding congestion and TNSS was 60 minutes and 30 minutes, respectively. The median onset of action for PF-03654764 + fexofenadine against TNSS was 60 minutes.

\section{Adverse events}

There were no serious adverse events (SAEs). Systolic BP increases from baseline $\geq 30 \mathrm{~mm} \mathrm{Hg}$ were experienced by 2/61 and 1/15 participants receiving fexofenadine + pseudoephedrine and placebo, respectively. Increases in diastolic $\mathrm{BP} \geq 30 \mathrm{~mm} \mathrm{Hg}$ were experienced by $1 / 47$, 4/61, 1/15 participants receiving PF-03654764 + fexofenadine, fexofenadine + pseudoephedrine and placebo, respectively. Out of the 64 participants who were randomized, four, two, one, and zero discontinued during treatment with PF-03654764 + fexofenadine, pseudoephedrine + fexofenadine, PF-03654764, and placebo, respectively. Two participants, both receiving PF-03654764 + fexofenadine, discontinued due to AEs that were considered to be treatment-related. As mentioned above, one participant never received placebo and one never received PF-03654764, thus sample sizes for both of those groups are fifteen participants for AE analysis. Three participants slated to receive fexofenadine + pseudoephedrine were never treated due to discontinuations in previous study 

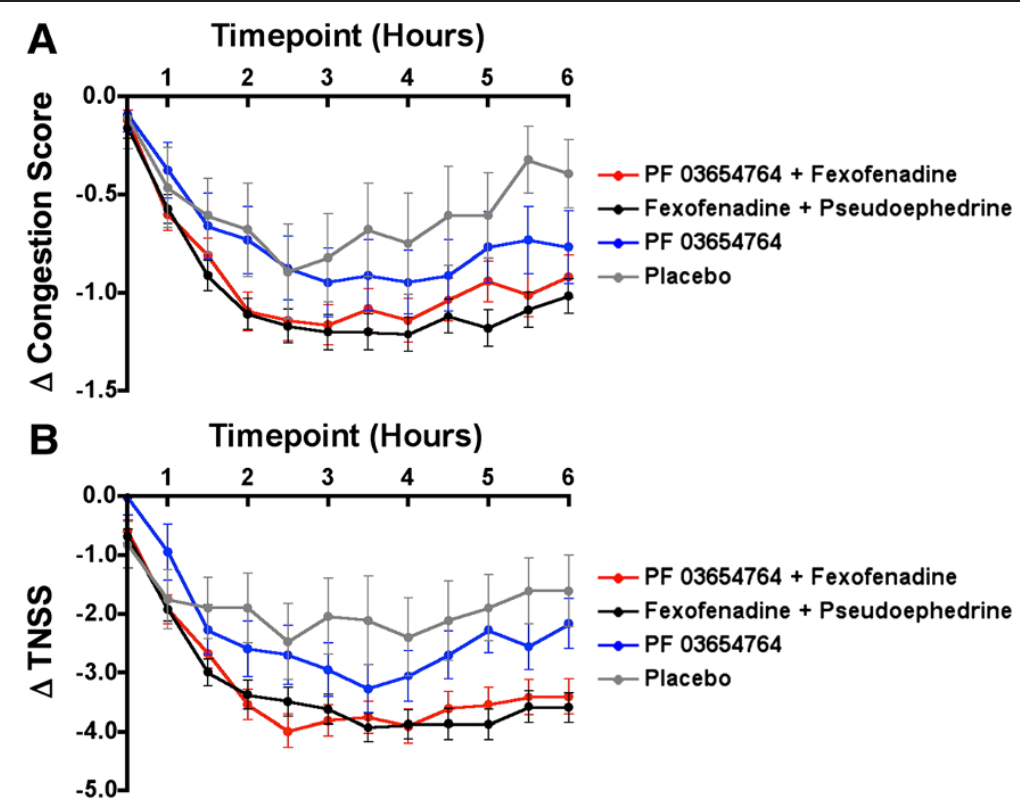

Figure 1 Time-course of change in symptom scores post-treatment. Exploratory visualization of the change in symptom scores ( $\triangle$ to baseline) are shown for A) Congestion, and B) Total Nasal Symptom Score (TNSS) from time of drug administration (0 hours) to 6 hours posttreatment. Lines and error bars represent the raw means and standard errors of the means for each of the treatments over time. It includes all participant study periods in which a participant was administered a treatment and remained in the EEU for the entire study period (excludes those periods where a participant discontinued the study without completing the visit). The $y$-intercept represents baseline, defined as the mean of the last two pre-treatment symptom scores $(-0.5 \mathrm{H}$ and $\mathrm{OH})$. Samples sizes were; $n=86,96,28$ and 14 for PF-03654764 + fexofenadine, fexofenadine + pseudoephedrine, PF-03654764, and placebo, respectively.

sessions. The incidence of AEs, both all causality and treatment-related, was greater in the PF-03654764-alone and PF-03654764 + fexofenadine groups, compared to the placebo and pseudoephedrine + fexofenadine groups (Table 5). The most common treatment-related AEs were insomnia, headache and nausea (Table 6).

\section{Discussion}

In this study we examined the combination of the $\mathrm{H}_{3}$ receptor antagonist, PF-03654764, and the $\mathrm{H}_{1}$ receptor antihistamine, fexofenadine, for the first time as a potential treatment for allergic rhinitis. This investigational treatment was not superior to established treatment. In

Table 3 Mixed model ANCOVA of mean congestion and TNSS scores (2-6 hours)

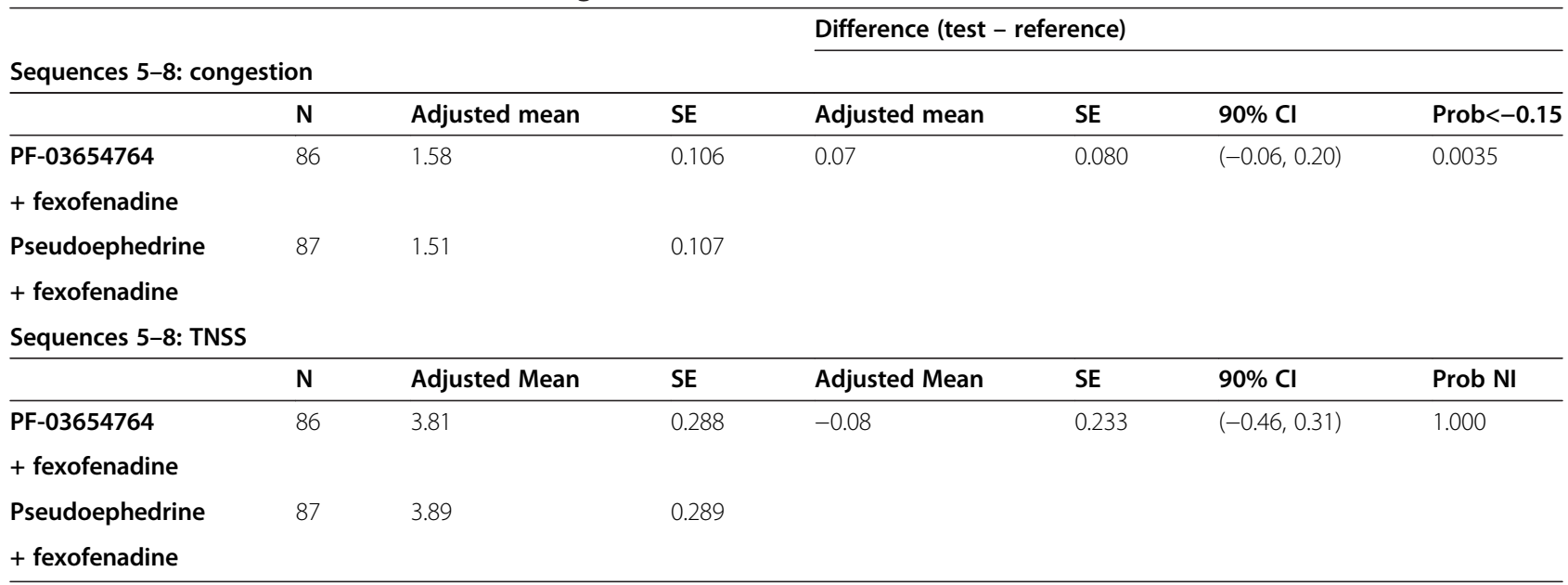

The primary analysis consisted of a mixed effects ANCOVA with period and treatment fixed effects and subject random effect, employing sequences 5-8 to compare PF-03654764.

+ fexofenadine to pseudoephedrine + fexofenadine. $\mathrm{N}=$ number of non-missing observations included in the analysis. 
Table 4 Post-Hoc analysis of mean symptom scores $(2 \mathrm{H}-6 \mathrm{H})$

\begin{tabular}{|c|c|c|c|c|c|}
\hline Treatment & $\mathbf{N}$ & Parameter & Mean \pm SE & 95\% Confidence interval & Adj. p-value to placebo \\
\hline \multirow[t]{2}{*}{ Placebo } & 14 & Congestion & $2.00 \pm 0.18$ & $(1.64,2.36)$ & $\mathrm{N} / \mathrm{A}$ \\
\hline & & TNSS & $5.51 \pm 0.50$ & $(4.53,6.49)$ & N/A \\
\hline \multirow[t]{2}{*}{ PF-03654764 } & 28 & Congestion & $1.90 \pm 0.15$ & $(1.59,2.20)$ & 0.939 \\
\hline & & TNSS & $4.84 \pm 0.42$ & $(4.00,5.67)$ & 0.186 \\
\hline \multirow[t]{2}{*}{ PF-03654764 + fexofenadine } & 86 & Congestion & $1.58 \pm 0.10$ & $(1.39,1.78)$ & 0.138 \\
\hline & & TNSS & $3.63 \pm 0.27$ & $(3.10,4.16)$ & 0.001 \\
\hline \multirow[t]{2}{*}{ Pseudoephedrine + fexofenadine } & 97 & Congestion & $1.50 \pm 0.09$ & $(1.31,1.68)$ & 0.034 \\
\hline & & TNSS & $3.70 \pm 0.25$ & $(3.20,4.20)$ & 0.003 \\
\hline
\end{tabular}

Mean symptom scores for congestion and Total Nasal Symptom Score (TNSS) were calculated by taking the least squares mean between $2 \mathrm{H}$ and $6 \mathrm{H}$ posttreatment. Standard error (SE) of the mean and $95 \%$ confidence intervals were also calculated for each treatment. $\mathrm{N}=$ number of participant study periods on each treatment. Groups were compared using a mixed model ANCOVA and the Tukey-Kramer adjustment was used to control for multiple comparison.

post-hoc analyses we demonstrated that PF-03654764+ fexofenadine significantly reduced Total Nasal Symptom Score (TNSS), relative to placebo. Although this study was not powered to conduct statistical evaluations of safety, the incidence of adverse events (AEs) was greater in PF-03654764-treated groups, compared to existing treatment or placebo.

\section{Nasal congestion}

The primary objective of this study was to compare the effect of PF-03654764 + fexofenadine on allergic rhinitisinduced nasal congestion to a commercially available dose of fexofenadine + pseudoephedrine. Neither PF-03654764 nor the PF-03654764 + fexofenadine combination was effective at reducing congestion. Additionally, these treatments did not meet the decision criteria for superiority over existing therapy. While PF-03654764 was not significantly better than placebo, the combination with fexofenadine was significantly better than PF-03654764 by itself on TNSS, and the combination of PF-03654764 with fexofenadine was significantly better than placebo on TNSS.
This posits the question of whether the results are due to the fexofenadine and not PF-03654764. Dose adjustment studies would be able to address this issue and determine if changes in oral dose of PF-03654764 affect the outcome of the experiment. In Stokes et al. there was a clear dosedependent phenomenon with a very similar $\mathrm{H}_{3}$ receptor antagonist, and it would be interesting to see if a similar pattern exists with PF-03654764.

\section{$\mathrm{H}_{3}$ receptor antagonists and nasal congestion}

A previous clinical study investigated dual $\mathrm{H}_{1} / \mathrm{H}_{3}$ receptor interference in an environmental challenge chamber [16]. Both nasal blockage and TNSS were improved, compared to placebo, but the treatment similarly failed to prove superior to existing treatment, in that case, cetirizine, an $\mathrm{H}_{1}$ receptor antihistamine [16]. As that study employed a non-specific molecule, and an active control that is not effective against congestion, this study was targeted towards examining a specific $\mathrm{H}_{3}$ receptor antagonist using an alternate active control, pseudoephedrine + fexofenadine.

Table 5 Summary of treatment-emergent adverse events by participant

\begin{tabular}{|c|c|c|c|c|}
\hline Adverse Event (AE) & $\begin{array}{l}\text { PF-03654764 + fexofenadine } \\
(\mathrm{N}=48)\end{array}$ & $\begin{array}{l}\text { PF-03654764 } \\
(N=15)\end{array}$ & $\begin{array}{l}\text { Pseudoephedrine + fexofenadine } \\
(\mathrm{N}=61)\end{array}$ & Placebo $(n=15)$ \\
\hline \multicolumn{5}{|l|}{ All Causalities } \\
\hline Number of AEs & 116 & 39 & 30 & 3 \\
\hline Participants with AEs & $36(75)$ & $12(80)$ & $18(29.5)$ & $3(20)$ \\
\hline Participants with severe AEs & $23(49)$ & $6(40)$ & $4(6.6)$ & 0 \\
\hline Participants discontinued due to AEs & $2(4.2)$ & $1(6.7)$ & 0 & 0 \\
\hline \multicolumn{5}{|l|}{ Treatment-Related } \\
\hline Number of AEs & 83 & 30 & 11 & 0 \\
\hline Participants with AEs & $22(45.8)$ & $11(73.3)$ & $6(9.8)$ & 0 \\
\hline Participants with severe AEs & $17(35.4)$ & $6(40.0)$ & $2(3.3)$ & 0 \\
\hline Participants discontinued due to AEs & $2(4.2)$ & 0 & 0 & 0 \\
\hline
\end{tabular}

Summary of AEs by participant across all dosing periods. $\mathrm{N}$ values represent the number of participants randomized to a sequence receiving one or more administrations of the treatment that were actually administered the treatment. In brackets, the percentage of participants experiencing adverse events with that treatment is given. Note that participants had twice as many opportunities to experience AEs on a particular treatment if they received the same treatment during two separate dosing periods. 
Table 6 Incidence of most frequent treatment-related adverse events ( $\geq 5 \%$ per treatment, by participant)

\begin{tabular}{|c|c|c|c|c|}
\hline Adverse Event (AE) & $\begin{array}{l}\text { PF-03654764 + fexofenadine } \\
(\mathrm{N}=48)\end{array}$ & $\begin{array}{l}\text { PF-03654764 } \\
(\mathrm{N}=15)\end{array}$ & $\begin{array}{l}\text { Pseudoephedrine + fexofenadine } \\
(\mathrm{N}=61)\end{array}$ & Placebo $(\mathrm{N}=15)$ \\
\hline Insomnia & $10(20.8)$ & $5(33.3)$ & $3(4.9)$ & 0 \\
\hline Headache & $9(18.8)$ & $3(20.0)$ & $1(1.6)$ & 0 \\
\hline Nausea & $9(18.8)$ & $4(26.7)$ & $1(1.6)$ & 0 \\
\hline Dysgeusia & $5(10.4)$ & 0 & $1(1.6)$ & 0 \\
\hline Hot flush & $4(8.3)$ & $1(6.7)$ & $1(1.6)$ & 0 \\
\hline Nightmare & $4(8.3)$ & 0 & 0 & 0 \\
\hline Abnormal Dreams & $3(6.3)$ & 0 & 0 & 0 \\
\hline Dizziness & $3(6.3)$ & $1(6.7)$ & $2(3.3)$ & 0 \\
\hline Malaise & $3(6.3)$ & 0 & 0 & 0 \\
\hline Night Sweats & $3(6.3)$ & $3(20.0)$ & 0 & 0 \\
\hline Tachycardia & $3(6.3)$ & 0 & 0 & 0 \\
\hline Diarrhea & $2(4.2)$ & $1(6.7)$ & 0 & 0 \\
\hline Palpitations & $2(4.2)$ & $1(6.7)$ & $1(1.6)$ & 0 \\
\hline Fatigue & $1(2.1)$ & $1(6.7)$ & 0 & 0 \\
\hline Hallucination & $1(2.1)$ & $2(13.3)$ & 0 & 0 \\
\hline Upper abdominal pain & 0 & $1(6.7)$ & 0 & 0 \\
\hline Feeling Jittery & 0 & $1(6.7)$ & 0 & 0 \\
\hline Feeling of body temperature change & 0 & $1(6.7)$ & 0 & 0 \\
\hline Cognitive disorder & 0 & $1(6.7)$ & 0 & 0 \\
\hline Migraine & 0 & $1(6.7)$ & 0 & 0 \\
\hline Parosmia & 0 & $1(6.7)$ & 0 & 0 \\
\hline Anxiety & 0 & $1(6.7)$ & 0 & 0 \\
\hline Hyperhidrosis & 0 & $1(6.7)$ & 0 & 0 \\
\hline
\end{tabular}

$\mathrm{N}=$ number of participants (percentage of total receiving that treatment). AEs were ranked in order of decreasing frequency by PF-03654764 + fexofenadine (treatment of interest).

Recently, Stokes et al. employed acoustic rhinometry to measure changes in minimum nasal cross-sectional area and nasal volume after treatment with PF-03654746 + fexofenadine $\left(\right.$ an $\mathrm{H}_{3}$ receptor antagonist with a similar structure to PF-03654764) [11]. The treatment significantly reduced subjective congestion scores, compared to placebo, but improvements in rhinometry measurements were not detected [11]. Those results may be explained in view of the disconnect between perception of nasal airflow and congestion and physical characteristics of intranasal space. However, since our primary objective was to see the efficacy on congestion, the non-significant response to $\mathrm{H}_{3}$ antagonism to measured vascular congestion in humans is important. As $5 \mathrm{mg}$ of PF-03654764 yields a plasma concentration of approximately $10 \times \mathrm{Ki}$ (10 times the binding affinity of PF-03654764 for the $\mathrm{H}_{3}$ receptor), effective $\mathrm{H}_{3}$ receptor antagonism should have been achieved in our study. However, Stokes and colleagues employed a similar but distinct $\mathrm{H}_{3}$ antagonist to the one used herein, with a relatively higher dose (up to $30 \times \mathrm{Ki}$ ) [11].

\section{Experimental allergen challenge methods}

Major differences between our protocol and Stokes et al. may also drive some of the differences in our findings. Timing of symptom development in relation to drug administration and the allergen challenge method employed are key. Stokes et al. investigated prophylactic potential, performing the nasal allergen provocation post-drug administration at the time that the drug serum concentration was estimated to be maximal [11]. Ours is the first study to examine the potential for specific $\mathrm{H}_{3}$ receptor antagonists to relieve pre-existing allergy symptoms induced by inhalation of allergen in the ambient air. We administered the study drug after 2 hours of allergen exposure, followed by an additional 6 hours of post-drug allergen exposure and symptom recording and were able to report the onset of action against allergic rhinitis symptoms for the first time. The advantages and disadvantages of different methods of allergen challenge for evaluating novel therapeutic preparations have been discussed elsewhere $[18,22]$. In brief, nasal allergen provocation tests have the advantage of focusing on a smaller number of participants 
at a time, enabling the collection of data such as acoustic rhinometry. However, as Stokes et al. reported no significant effect on minimum nasal cross-sectional area or nasal volume [11], the present study did not evaluate that outcome. Instead, we employed the EEU to allow larger numbers of study volunteers to be simultaneously exposed to standardized ambient levels of ragweed pollen, providing the recognized advantage of a more natural mode of allergen exposure [18]. Ragweed allergen was chosen, as it is one of the most common aeroallergens that naturally induces allergic rhinitis symptoms in our study population, and the level of exposure in the EEU was consistent with peak seasonal levels [23,24]. European annual mean pollen counts of ragweed are as high as 7800 grains $/ \mathrm{m}^{3}$ $[3,25]$. Although ragweed pollen is not as common in the United States, weed pollens do reach as high as 2900 grains $/ \mathrm{m}^{3}[3,26]$ and tree pollen is known to reach over 8000 grains $/ \mathrm{m}^{3}[3,27]$. It was recently demonstrated that there is a high degree of concordance between allergic symptoms induced on exposure to pollen in an environmental exposure unit and those experienced during the natural season [28]. An outpatient study during ragweed season may have achieved similar efficacy results, but could not have been used to evaluate the onset of action [18].

\section{Onset of action}

The time to onset of action for PF-03654764 + fexofenadine has not previously been reported. In this study we report that it is 60 minutes for clinically important improvement in TNSS. For fexofenadine + pseudoephedrine we determined a 60 minute onset of action against congestion, and a 30 minute onset of action against TNSS. We previously found that fexofenadine alone provided clinically important relief from allergic rhinitis symptoms at 60 minutes [29]. The onset of action for fexofenadine + pseudoephedrine has been previously reported by Berkowitz et al. to be 45 minutes [30]. Differences in reported onset of action likely result from timing of diary card collection and the symptoms included in composite scores. Overall, the onset of action is remarkably consistent between environmental exposure unit studies, and the slower onset of action against congestion compared to TNSS may reflect a lag in the subjective perception of nasal fullness compared to the decline in number of sneezes and other symptoms.

\section{Adverse events}

In this study PF-03654764-treated groups exhibited a higher incidence of AEs, compared to pseudoephedrine + fexofenadine or placebo. Previously, Stokes et al. reported greater AEs in participants treated with the similar $\mathrm{H}_{3}$ receptor antagonist, PF-03654746 [11]. Many of the AEs in this study are consistent with those reported by Stokes et al., including insomnia, hallucination and feeling jittery [11]. $\mathrm{H}_{3}$ receptors have been demonstrated in the central nervous system, where they regulate other neurotransmitters (e.g. acetylcholine and norepinephrine) [17,31]. Additionally, PF-03654764 is believed to be fully central nervous system penetrant, which may also help to explain the finding of increased AEs and their nature. It was envisioned that the combination of a novel $\mathrm{H}_{3}$ receptor antagonist with an established antihistamine may provide relief with a superior safety profile for those who are contraindicated to treatment with sympathomimetic agents $[11,17]$. Another $\mathrm{H}_{3}$ receptor antagonist with a lesser penetrance into the central nervous system may exhibit a more favorable safety profile, or even increased efficacy against allergic rhinitis symptoms.

\section{Limitations}

A limitation of this study is that we are unable to make a direct comparison between fexofenadine and the fexofenadine + PF-03654764 combination. A fexofenadine monotherapy treatment was not included in this study, as the primary goal of the trial was to assess the effects of fexofenadine + PF-03654764 vs. the existing combination therapy of fexofenadine + pseudoephedrine. In future studies it would be interesting to include a fexofenadine monotherapy group so that the effect difference could be compared to $\mathrm{H}_{3}$ antagonist monotherapy to assess synergistic/antagonistic effects.

Also of note, it has recently been demonstrated that common antihistamines may not act as simple antagonists, but rather as inverse agonists, stabilizing inactive forms of the $\mathrm{H}_{1}$ and $\mathrm{H}_{2}$ receptors [32-34]. Inverse agonism describes the ability of certain "antagonists" to reduce the activity of receptor systems that are active in the absence of agonists [35]. However, whether inverse agonism is essential or clinically important for antihistamines has not been clarified yet [35]. Thus far, the published literature indicates that PF-03654764 is a potent and specific $\mathrm{H}_{3}$ receptor antagonist [17]. However, other $\mathrm{H}_{3}$ receptor "antagonists" have recently been shown to exhibit inverse agonist activity [36]. Further biochemical and pharmacological studies are needed to understand the mechanism of action in detail.

\section{Conclusions}

In conclusion, we demonstrated that the $\mathrm{H}_{3}$ receptor antagonist, PF-03654764, plus the $\mathrm{H}_{1}$ receptor antagonist, fexofenadine, did not achieve superiority over established treatment in a double-blind, placebo-controlled crossover study in the Environmental Exposure Unit. However, we demonstrated non-inferiority compared to pseudoephedrine + fexofenadine. 


\section{Additional file}

\section{Additional file 1: Supplementary Methods.}

\section{Abbreviations}

AE: Adverse event; ANCOVA: Analysis of covariance; BP: Blood pressure; $\mathrm{Cl}$ : Confidence interval; EEU: Environmental exposure unit; Ki: Binding affinity; MMRM: Mixed model repeated measures; OA: Onset of action; PF-03654764: Trans-N-ethyl-3-fluoro-3-[3-fluoro-4-(pyrrolidinylmethyl) phenyl] cyclobutanecarboxamide; SAE: Serious adverse event; SE: Standard error; TNSS: Total nasal symptom score.

\section{Competing interest}

The authors declare that they have no conflicts of interest. RJA and FH were employees of Pfizer Ltd., United Kingdom, at the time of study conduct.

\section{Authors' contributions}

MLN carried out data analysis and interpretation, graphing and preparing figures, drafting the article. TW was involved in the conception and design of the study and carried out the collection of data with regards to pollen exposure and pollen levels during the challenges, analysis and interpretation of pollen data. LMS was involved in the conception and design of the study with regards to ethics, measures and endpoints, and carried out data collection. BGH was involved in the conception and design of the study with regards to logging symptom score data, data collection, security and export for statistical analysis. RJA was involved in the conception and design of the study with regards to study drug and major endpoints and carried out interpretation of data. FH was involved in the conception and design of the study with regards to statistics, and carried out data interpretation and statistical analysis of the primary outcomes. XS carried out post-hoc statistical analysis. AGD was involved in the conception and design of the study with regards to post-hoc statistical analysis, and carried out interpretation of data. AKE was involved in the conception and design of the study with regards to pollen exposure, clinical outcomes, symptom scores, and carried out the collection and interpretation of data. All Authors contributed to revising the manuscript for important intellectual content and gave their final approval of the version to be published.

\section{Acknowledgments}

The authors would like to thank the large number of study doctors, nurses and support staff of the environmental exposure unit (EEU). This study was supported by Pfizer, UK. MLN was supported by the John Alexander Stewart Award, Department of Medicine, Queen's University, a Canadian Allergy and Immune Diseases Advanced Training Initiative (CAIDATI) Award, AllerGen N.C. E., and an Ontario Ministry of Research and Innovation Award.

\section{Author details}

'Department of Biomedical and Molecular Sciences, Queen's University, Kingston, Ontario, Canada. ${ }^{2}$ Allergy Research Unit, Kingston General Hospital, Kingston, Ontario, Canada. ${ }^{3}$ Pfizer Ltd., Sandwich, UK. ${ }^{4}$ Clinical Research Centre, Kingston General Hospital, Kingston, Ontario, Canada. ${ }^{5}$ Division of Allergy and Immunology, Department of Medicine, Queen's University, Doran 1, Kingston General Hospital, 76 Stuart Street, Kingston, ON K7L 2 V7, Canada.

Received: 17 April 2014 Accepted: 15 June 2014

Published: 3 July 2014

\section{References}

1. Bousquet J, Van Cauwenberge $P$, Khaltaev N: Allergic rhinitis and its impact on asthma. J Allergy Clin Immunol 2001, 108:S147-S334.

2. Phan $\mathrm{H}$, Moeller ML, Nahata MC: Treatment of allergic rhinitis in infants and children: efficacy and safety of second-generation antihistamines and the leukotriene receptor antagonist montelukast. Drugs 2009, 69:2541-2576

3. Simons FE: Comparative pharmacology of $\mathrm{H} 1$ antihistamines: clinical relevance. Am J Med 2002, 113(Suppl 9A):38S-46S.

4. del Cuvillo A, Mullol J, Bartra J, Davila I, Jauregui I, Montoro J, Sastre J, Valero AL: Comparative pharmacology of the $\mathrm{H} 1$ antihistamines. J Investig Allergol Clin Immunol 2006, 16(Suppl 1):3-12.

5. Nathan RA: The burden of allergic rhinitis. Allergy Asthma Proc 2007, 28:3-9.
6. Nathan RA, Meltzer EO, Derebery J, Campbell UB, Stang PE, Corrao MA Allen $\mathrm{G}$, Stanford R: The prevalence of nasal symptoms attributed to allergies in the United States: findings from the burden of rhinitis in an America survey. Allergy Asthma Proc 2008, 29:600-608.

7. Djukanovic R, Wilson SJ, Howarth PH: Pathology of rhinitis and bronchial asthma. Clin Exp Allergy 1996, 26(Suppl 3):44-51.

8. Chervinsky P, Nayak A, Rooklin A, Danzig M: Efficacy and safety of desloratadine/pseudoephedrine tablet, $2.5 / 120 \mathrm{mg}$ two times a day, versus individual components in the treatment of patients with seasonal allergic rhinitis. Allergy Asthma Proc 2005, 26:391-396.

9. Moinuddin R, DeTineo M, Maleckar B, Naclerio RM, Baroody FM: Comparison of the combinations of fexofenadine-pseudoephedrine and loratadine-montelukast in the treatment of seasonal allergic rhinitis. Ann Allergy Asthma Immunol 2004, 92:73-79.

10. Empey DW, Young GA, Letley E, John GC, Smith P, McDonnell KA, Bagg LR, Hughes DT: Dose-response study of the nasal decongestant and cardiovascular effects of pseudoephedrine. Br J Clin Pharmacol 1980, 9:351-358.

11. Stokes JR, Romero FA Jr, Allan RJ, Phillips PG, Hackman F, Misfeldt J, Casale TB: The effects of an $\mathrm{H} 3$ receptor antagonist (PF-03654746) with fexofenadine on reducing allergic rhinitis symptoms. J Allergy Clin Immunol 2012, 129:409-412. 12 e1-2.

12. McLeod RL, Mingo GG, Kreutner W, Hey JA: Effect of combined histamine $\mathrm{H} 1$ and $\mathrm{H} 3$ receptor blockade on cutaneous microvascular permeability elicited by compound 48/80. Life Sci 2005, 76:1787-1794.

13. McLeod RL, Mingo GG, Herczku C, DeGennaro-Culver F, Kreutner W, Egan RW, Hey JA: Combined histamine $\mathrm{H} 1$ and $\mathrm{H} 3$ receptor blockade produces nasal decongestion in an experimental model of nasal congestion. Am J Rhinol 1999, 13:391-399.

14. Varty LM, Gustafson E, Laverty M, Hey JA: Activation of histamine H3 receptors in human nasal mucosa inhibits sympathetic vasoconstriction. Eur J Pharmacol 2004, 484:83-89.

15. Varty LM, Hey JA: Histamine $\mathrm{H} 3$ receptor activation inhibits neurogenic sympathetic vasoconstriction in porcine nasal mucosa. Eur J Pharmacol 2002, 452:339-345

16. Daley-Yates P, Ambery C, Sweeney L, Watson J, Oliver A, McQuade B: The efficacy and tolerability of two novel $\mathrm{H}(1) / \mathrm{H}(3)$ receptor antagonists in seasonal allergic rhinitis. Int Arch Allergy Immunol 2012, 158:84-98.

17. Wager TT, Pettersen BA, Schmidt AW, Spracklin DK, Mente S, Butler TW, Howard H, Lettiere DJ, Rubitski DM, Wong DF, Nedza FM, Nelson FR, Rollema H, Raggon JW, Aubrecht J, Freeman JK, Marcek JM, Cianfrogna J, Cook KW, James LC, Chatman LA, Iredale PA, Banker MJ, Homiski ML, Munzner JB, Chandrasekaran RY: Discovery of two clinical histamine $\mathrm{H}(3)$ receptor antagonists: trans-N-ethyl-3-fluoro-3-[3-fluoro-4-(pyrrolidinylmethyl)phenyl] cyclo-butanecarbox amide (PF-03654746) and trans-3-fluoro-3-[3-fluoro-4(pyrrolidin-1-ylmethyl)phenyl]-N-(2-methylpropyl)cyc lobutanecarboxamide (PF-03654764). J Med Chem 2011, 54:7602-7620.

18. Day JH, Ellis AK, Rafeiro E, Ratz JD, Briscoe MP: Experimental models for the evaluation of treatment of allergic rhinitis. Ann Allergy Asthma Immunol 2006, 96:263-277. quiz 77-8, 315.

19. Ellis AK, Ratz JD, Day AG, Day JH: Factors that affect the allergic rhinitis response to ragweed allergen exposure. Ann Allergy Asthma Immunol 2010, 104:293-298.

20. Pfizer: PF-03654764 Investigator's Brochure. In Internal clinical and non-clinical studies. 2009

21. Norusis MJ: SPSS 11.0 Guide to Data Analysis. Chapter 22: Analyzing Residuals. New Jersey: Prentice Hall; 2002.

22. Akerlund A, Andersson M, Leflein J, Lildholdt T, Mygind N: Clinical trial design, nasal allergen challenge models, and considerations of relevance to pediatrics, nasal polyposis, and different classes of medication. J Allergy Clin Immunol 2005, 115:S460-S482.

23. Day JH, Briscoe MP: Environmental exposure unit: a system to test antiallergic treatment. Ann Allergy Asthma Immunol 1999, 83:83-89. quiz 9-93.

24. Ellis AK, Steacy LM, Walker T: Clinical Validation of Controlled Grass Pollen Challenge in the Environmental Exposure Unit (EEU) [abstract]. J Allergy Clin Immunol 2012, 129:AB112.

25. Deak AJ, Makra L, Matyasovszky I, Csepe Z, Muladi B: Climate sensitivity of allergenic taxa in Central Europe associated with new climate change related forces. Sci Total Environ 2013, 442:36-47.

26. Port A, Hein J, Wolff A, Bielory L: Aeroallergen prevalence in the northern New Jersey-New York City metropolitan area: a 15-year summary. Ann Allergy Asthma Immunol 2006, 96:687-691. 
27. Dellavalle CT, Triche EW, Bell ML: Spatial and temporal modeling of daily pollen concentrations. Int J Biometeorol 2012, 56:183-194.

28. Jacobs RL, Harper N, He W, Andrews CP, Rather CG, Ramirez DA, Ahuja SK: Responses to ragweed pollen in a pollen challenge chamber versus seasonal exposure identify allergic rhinoconjunctivitis endotypes. J Allergy Clin Immunol 2012, 130:122-7 e8.

29. Day JH, Briscoe MP, Welsh A, Smith JN, Clark A, Ellis AK, Mason J: Onset of action, efficacy, and safety of a single dose of fexofenadine hydrochloride for ragweed allergy using an environmental exposure unit. Ann Allergy Asthma Immunol 1997, 79:533-540.

30. Berkowitz RB, Woodworth GG, Lutz C, Weiler K, Weiler J, Moss M, Meeves S: Onset of action, efficacy, and safety of fexofenadine $60 \mathrm{mg} /$ pseudoephedrine $120 \mathrm{mg}$ versus placebo in the Atlanta allergen exposure unit. Ann Allergy Asthma Immunol 2002, 89:38-45.

31. Weisler RH, Pandina GJ, Daly EJ, Cooper K, Gassmann-Mayer C: Randomized clinical study of a histamine $\mathrm{H} 3$ receptor antagonist for the treatment of adults with attention-deficit hyperactivity disorder. CNS Drugs 2012, 26:421-434

32. Smit MJ, Timmerman $\mathrm{H}$, Alewijnse AE, Leurs R: From histamine $\mathrm{H} 2$ receptor regulation to reclassification of $\mathrm{H} 2$ antagonists; inverse agonism as the basis for H2 receptor upregulation. Receptors Channels 1998, 5:99-102.

33. Bakker RA, Wieland $\mathrm{K}$, Timmerman $\mathrm{H}$, Leurs R: Constitutive activity of the histamine $H(1)$ receptor reveals inverse agonism of histamine $H(1)$ receptor antagonists. Eur J Pharmacol 2000, 387:R5-R7.

34. Wu RL, Anthes JC, Kreutner W, Harris AG, West RE Jr: Desloratadine inhibits constitutive and histamine-stimulated nuclear factor-kappaB activity consistent with inverse agonism at the histamine $\mathrm{H} 1$ Receptor. Int Arch Allergy Immunol 2004, 135:313-318.

35. Monczor F, Fernandez N, Fitzsimons CP, Shayo C, Davio C: Antihistaminergics and inverse agonism: potential therapeutic applications. Eur J Pharmacol 2013, 715:26-32

36. Wieland K, Bongers G, Yamamoto Y, Hashimoto T, Yamatodani A, Menge WM, Timmerman H, Lovenberg TW, Leurs R: Constitutive activity of histamine $\mathrm{h}(3)$ receptors stably expressed in SK-N-MC cells: display of agonism and inverse agonism by $\mathrm{H}(3)$ antagonists. J Pharmacol Exp Ther 2001, 299:908-914.

doi:10.1186/1710-1492-10-33

Cite this article as: North et al: Add-on histamine receptor-3 antagonist for allergic rhinitis: a double blind randomized crossover trial using the environmental exposure unit. Allergy, Asthma \& Clinical Immunology 2014 10:33

\section{Submit your next manuscript to BioMed Central and take full advantage of:}

- Convenient online submission

- Thorough peer review

- No space constraints or color figure charges

- Immediate publication on acceptance

- Inclusion in PubMed, CAS, Scopus and Google Scholar

- Research which is freely available for redistribution 